\title{
ПРОБЛЕМЫ ПОВЫШЕНИЯ КАЧЕСТВА ОБРАЗОВАНИЯ В КОНТЕКСТЕ ПОВЫШЕНИЯ ЭФФЕКТИВНОСТИ ДЕЯТЕЛЬНОСТИ ВУЗОВ
}

\section{(c) 2019 Малянов Даниил Викторович}

ассистент, кафедра экономики и управления предприятиями и производственными комплексами Санкт-Петербургский государственный экономический университет, Россия, Санкт-Петербург

E-mail:daniil_malaynov@list.ru

В статье рассматривается проблема поиска инструментов преподавания в высшем профессиональном образовании в условиях ограниченного временного интервала при наличии проблем с восприятием информации современными студентами. Дано обоснование проблемы. Предложены инструменты со ссылкой на исторические и современные научно обоснованные педагогические подходы. Сами по себе инструменты не являются новыми для отечественного образования. Интерес представляют варианты их использования и возможности комбинированного использования. Предложенные варианты имеют обоснование.

Ключевые слова: образование, высшая школа, качество образования

В течении последних 10 лет активно ведутся разговоры о необходимости повышения качества высшего образования в России и повышения эффективности деятельности ВУЗов. Такая постановка вопроса характерна не только для государства, но и для бизнеса. На всех уровнях отмечается не только недостаток практических знаний, что, в целом, является давней болезнью нашего образования, но и серьезные проблемы с теоретической подготовкой, что всегда было сильной стороной выпускников наших ВУЗов. И это более опасная проблема. Все старания преподавателей объяснить практическую сторону учебных дисциплин бесполезны без знания теории. Конечно, можно решить эту проблему вспомнив хорошо забытое старое. Методики, материалы и даже люди есть. Но это не так просто как кажется. На сегодняшний день преподавательский состав профессионального образования сталкивается с рядом проблем, истоки которых лежат в современных подходах формирования системы образования, как бы громко это не звучало. Несмотря на то, что студенты с каждым годом хуже воспринимают материал, объем аудиторных часов сокращают в пользу внеаудиторной нагрузки. Восприимчивость к новому материалу ухудшается из-за неспособности современной молодежи удерживать длительное время незаученный материал ввиду увлеченности электронными средствами информации и их легкой доступности.

Исходя из этого, преподавателям необходимо искать возможности максимально эффективного использования доступных часов аудиторной нагрузки, а также новые формы быстрого и качественного закрепления материала в головах студентов.

Существует масса современных методов и форм обучения, но большинство из них изначально имеют возможность только точечного применения и требуют определенного уровня подготовки студентов.

С точки зрения возможности массового применения и отсутствия требований к готовности студентов наиболее интересным является метод визуализации фактологических данных. Он имеет глубокие исторические корни. Ян Амос Каменский (1592-1670) основоположник педагогики как науки, быстро осознал значение зрительного восприятия для процесса обучения и издал книгу «Мир чувственных вещей в картинках, или Изображение и наименование всех важнейших предметов в мире и действий в жизни» которую очень ценил и повелел издать Петр I [3]. В отечественной педагогике метод визуализации применяется давно, но, в основном, для показа студентам в рамках занятия. Последнее время все чаще из материала перестают делать тайну и передают студентам. На мой взгляд, это необходимо, но в виде бумажного носителя, а не электронного, т.к. в ином случае студенты перестают посещать занятия считая, что наличие лекционного материала заменит им все. Цель же преподавателя должна состоять в том, чтобы найти время на передачу дополнительной информации, т.е. компенсировать нехватку аудиторной нагрузки. В итоге, этот метод дает нам бесценный ресурс время. Практические решения могут быть разными: структурные рисунки, текст, сведенный в таблицу и т.д. (рис.1). 


\begin{tabular}{|c|c|}
\hline \multicolumn{2}{|r|}{ Транспорт предприятия } \\
\hline Признак & Характеристика \\
\hline 1. Зона применения & $\begin{array}{l}\text { 1.1. Внешний транспорт (для связи предприятия с внешними транспортными } \\
\text { системами): } \\
\text { - железными дорогами; } \\
\text { - аэропортами; } \\
\text { - речными и морскими портамии др. предприятиями. } \\
\text { 1.2. Внутризаводской - для перемещения грузов между цехами, участками, рабо- } \\
\text { чими местами. Он состоит: } \\
\text { - из межцехового транспорта; } \\
\text { - внутрицехового транспорта (для перемещения грузов между участками и рабо- } \\
\text { чими местами); } \\
\text { - межоперационного транспорта (для перемещения грузов между рабочими } \\
\text { местами). }\end{array}$ \\
\hline $\begin{array}{l}\text { 2. Вид транспортного } \\
\text { средства }\end{array}$ & $\begin{array}{l}\text { 2.1. Колесный транспорт } \\
\text { Железнодорожный } \\
\text { Автомобильный } \\
\text { Автопогрузчики } \\
\text { Электротранспорт (электрокары, вильчатые погрузчики, электротягачи) } \\
\text { 2.2. Транспортные конвейеры } \\
\text { 2.3. Монорельсовые дороги (в т.ч. с автоматическим адресованием грузов) } \\
\text { 2.4. Трубопроводный транспорт } \\
\text { 2.5. Пневмотранспорт } \\
\text { 2.6. Роботы и роботрейлеры }\end{array}$ \\
\hline
\end{tabular}

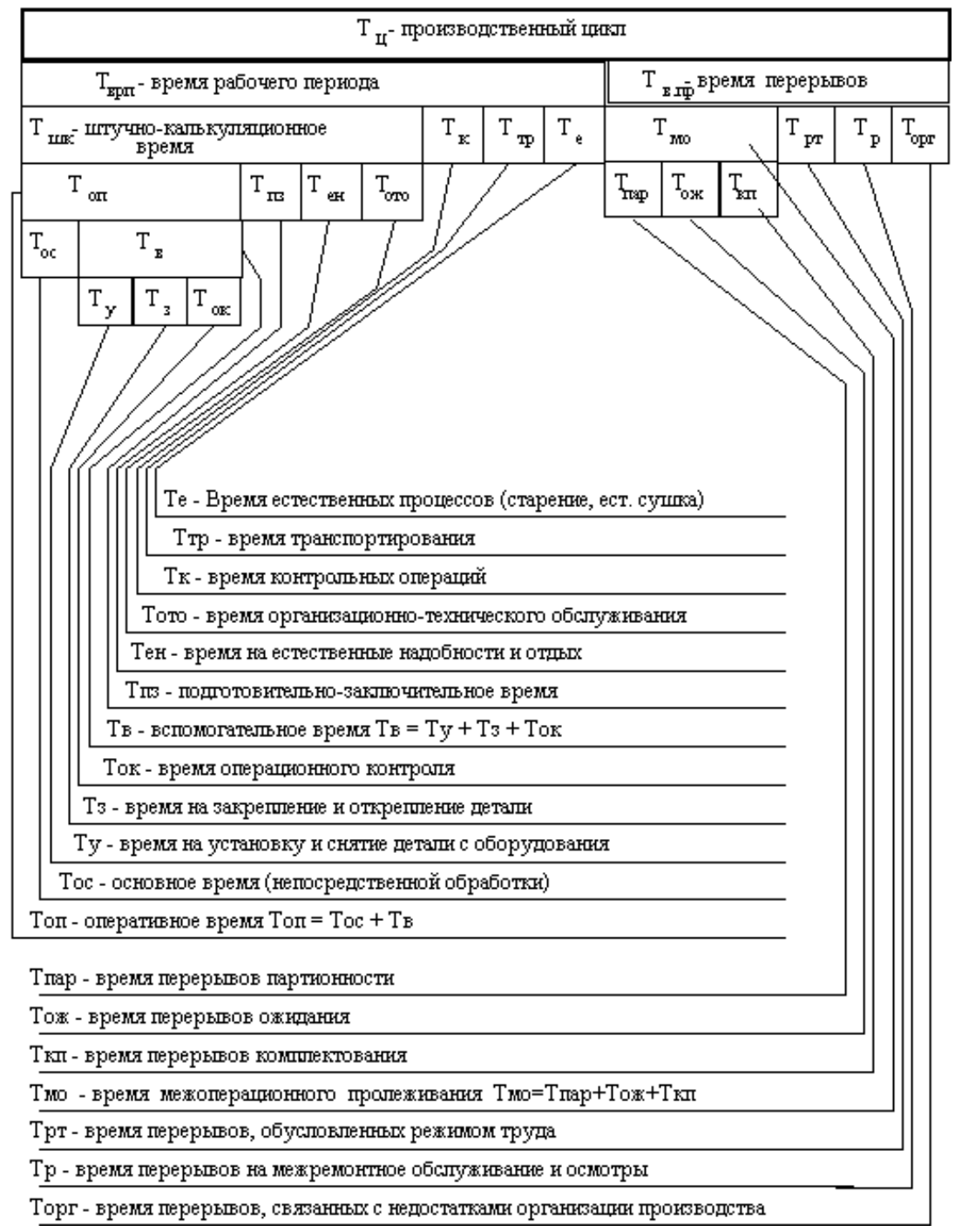

Puc. 1. Примеры визуализации текстового материала [9]. 
Уже давно существует мнение, что деление занятий на лекции и семинары не самый разумный подход. У него есть положительные стороны, но современные студенты, как я уже писалось выше, имеют низкую восприимчивость к новому материалу из-за неспособности удерживать длительное время незаученный материал. Таким образом, семинарское занятие через пару дней после лекции становиться неэффективным, а если больше 5 дней, то почти бесполезным. Фактически приходится повторять лекцию. Старая мудрость: «Повторение мать учения», почти не работает. Нужно от 200 до 400 повторов (по последним исследованиям) для запоминания информации молодежью. Следовательно, необходимо соединять эти формы обучения, что довольно давно практикуется в рамках модульных курсов в ведущих университетах мира.

Ценность интерактивным методов обучения не оспаривается большинством педагогических работников. Более того, наука педагогика начиналась с того, что знания рекомендовали подавать в игровой форме как минимум в двух возрастных группах: дети и подростки. Для взрослых людей игра как форма обучения не отрицалась. Я. Каменский предлагает непосредственно вводить в процесс обучения так называемую “школу-игру” с определенными элементами театрализации. Именно деятельность в форме игры давала возможность облегчить процесс обучения студентов, приближая их к жизненным ситуациям. Что интересно, под игрой Я. Коменский воспринимал не просто некоторое, в ряде случаев, веселое времяпровождение в декорированных костюма, а возможность достижения достаточно серьезных целей. Игра в данном случае носит обучающий и воспитательный характер, разыгрывая мир в чувственных картинах, что можно назвать деятельным подходом [3; 7]. Сегодня интерактив, как метод обучения, далеко выходит за понятие игры. В первую очередь это грамотно организованное общение между преподавателем и студентами и, что еще важнее, между студентами с целью формирования и закрепления знаний. Разнообразные деловые игры могут иметь как рамочный характер, так и высокую степень проработки, снижающую творческую активность, но закрепляющую методические навыки. В целом, интерактив близок современным студентам. Они с удовольствием существуют в этом формате.

Таким образом, можно сформировать ком- плексное решение.

1. Максимально возможно больший объем материала дисциплины необходимо визуализировать в рисунки, таблицы, схемы и т.д. Этот материал распечатывается и раздается студентам или рассылается перед занятием. Таким образом, у всех присутствующих есть значительный объем лекции в удобной для восприятия форме который им не надо записывать. Под запись дается материал определений и тот, который не удается визуализировать. Благодаря этому удается экономить до 80\% времени. Оно тратится на полноценное пояснение материала.

2. Пояснение материала осуществляется в рамках подходов принятых на семинарах. Т.е. мы совмещаем лекционные и семинарские занятия, что позволяет сразу же закреплять теоретический материал на основе практических примеров и подходов. Это позволяет преодолеть краткосрочность памяти современных студентов. К тому же они обладают глубоко практическим мышлением, что изначально влияет на восприятие материала. Таким образом, можно подавать материал не только более качественно, но и в рамках мироощущения молодежи, что повышает столь важный элемент обучения как добровольность восприятия в рамках внутреннего интереса обучаемого. Дополнительным элементом усиления желания учится, является возможность не только слушать, но и обсуждать, и даже спорить.

3. Исходя из возникающего в предыдущего пункта посыла, максимизация общения является жизненной необходимостью в рамках современной педагогики. Следовательно, разнообразные формы интерактивного обучения должны применяться во всех доступных проявлениях. Наиболее востребованным является организация общения. Стартовым посылом должен быть групповой диалог. Т.е. преподаватель разговаривает со студентами, выводя их на изучение и восприятие материала, опираясь на предоставленный визуализированный материал. При этом, нужно не подавать его как прописную истину, а доказывать в рамка практических примеров. Но делать это желательно через создание разнообразных проблемных ситуаций, из которых студенты должны искать выход сами. Наилучшим вариантом будет вывести общение на уровень управляемой дискуссии всей аудитории. Это важно не только для формирования ощущения участия студентов, но и для выведе- 
ния из тени значительной части обучаемых. Так как активность проявляют, обычно, не более $10 \%$ и еще 10-15\% участвуют в процессе периодически. Только массовая дискуссия способна их вырвать из «зоны комфорта». Следовательно, диалог - это не предел совершенства. Более того, по итогам коллективного обсуждения у студентов появляется ощущение, что этих знаний они достигли сами, а это идеальная ситуация восприятия нового и прочного усвоения материала. Естественно, что сформированный процесс обучения находится в непосредственной связи с мыслительной деятельностью обучающихся,и все закономерное и случайное, объяснимое и необъяснимое в учебном познании в значительной мере требует рассмотрения с позиций разу- ма (мышления) [4]. Для формирования практических навыков в рамках изучаемого материала в курс добавляется 1-2 деловые игры комплексного характера с заданием общих рамок, или 5-6 игр с высокой степенью проработки.

Таким образом, комплекс решений можно охарактеризовать следующим образом: визуальное давление, подкрепленное практическими ситуациями и обсужденное большинством участников общения. В некотором смысле, речь идет о психологическом программировании.

Все это может способствовать повышению эффективности и качества обучения, что особенно важно в рамках современных требований к высшей школе.

\section{Библиографический список}

1. ригораш О.В, Трубилин А.И. Интерактивные методы обучения в современном вузе // Научный журнал КубГАУ - Scientific Journal of KubSAU. 2014. № 101. URL: https://cyberleninka.ru/article/n/interaktivnye-metodyobucheniya-v-sovremennom-vuze-1.

2. Аронова, Г.А. Методика обучения взрослых: особенности лекционной формы подачи материала по гуманитарным дисциплинам [Электронный ресурс] // Фестиваль педагогических идей «Открытый урок»: [сайт].2012.

3. Лордкипанидзе Д. Ян Амос Коменский.- Москва; Педагогика, 1970

4. Нигматов З.Г., Шакирова Л.Р. Теория и технологии обучения в высшей школе: Курс лекций / Под ред. 3.Г. Нигматова. - Казань, 2012

5. Панина, Т. С. Современные способы активизации обучения: учебное пособие / Т. С. Панина, Л.Н. Вавилова; под ред. Т.С. Паниной. - 4-е изд., стер.- М.: Издательский центр «Академия», 2008. - 176 с.

6. Панфилова, А.П. Инновационные педагогические технологии: Активное обучение: учебное пособие / А.П. Панфилова.-М.: Издательский центр «Академия», 2009. - 192 с.

7. Семенова Н.А., Товарищева Ф.Д. Я.А. Коменский - основатель игровой технологии/Гуманитарное образование как императив развития гражданского общества. Сборник научно-методических материалов международного научно-образовательного форума СВФУ. Ответственные за выпуск: О.М. Чоросова, Р.Е. Герасимова, Л.Е. Манчурина, Н.И. Захарова. 2014.

8. Ступина, С.Б. Технологии интерактивного обучения в высшей школе: учебно-методическое пособие / С.Б. Ступина.-Саратов: Издательский центр «Наука», 2009. - 52 с.

9. Конспект лекций по дисциплине «Экономика предприятия» для студентов очной и заочной формы обучения специальности 6.030504 «Экономика предприятия». Харьков, 2011 